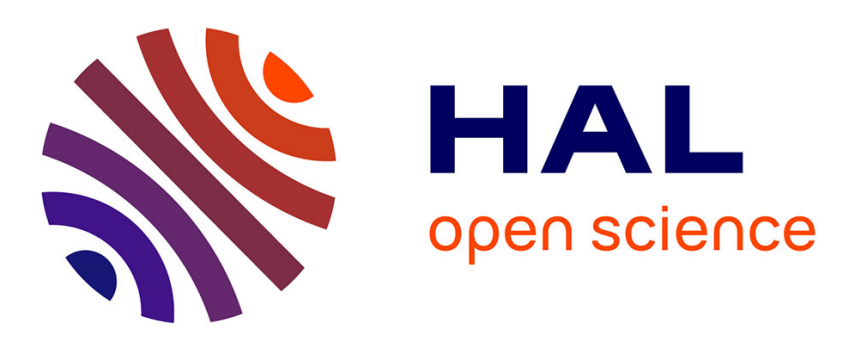

\title{
Early and Middle Pleistocene hominins from Atapuerca (Spain) show differences in dental developmental patterns
}

\author{
Mario Modesto-Mata, Rebeca García-González, Yuliet Quintino, Cecilia
} García-Campos, Marina Martínez de Pinillos, Laura Martín-Francés, María Martinón-Torres, Yann Heuzé, Eudald Carbonell, Juan Luis Arsuaga, et al.

\section{To cite this version:}

Mario Modesto-Mata, Rebeca García-González, Yuliet Quintino, Cecilia García-Campos, Marina Martínez de Pinillos, et al.. Early and Middle Pleistocene hominins from Atapuerca (Spain) show differences in dental developmental patterns. American Journal of Biological Anthropology, In press, 10.1002/ajpa.24487 . hal-03562257

\section{HAL Id: hal-03562257 https://hal.science/hal-03562257}

Submitted on 8 Feb 2022

HAL is a multi-disciplinary open access archive for the deposit and dissemination of scientific research documents, whether they are published or not. The documents may come from teaching and research institutions in France or abroad, or from public or private research centers.
L'archive ouverte pluridisciplinaire HAL, est destinée au dépôt et à la diffusion de documents scientifiques de niveau recherche, publiés ou non, émanant des établissements d'enseignement et de recherche français ou étrangers, des laboratoires publics ou privés. 


\section{Early and Middle Pleistocene hominins from Atapuerca (Spain) show differences in dental developmental patterns}

Mario Modesto-Mata1,3, ${ }^{*}$, Rebeca García-González ${ }^{*}$, Yuliet Quintino4 ${ }^{4}$, Cecilia GarcíaCampos $^{1,2}$, Marina Martínez de Pinillos ${ }^{1}$, Laura Martín-Francés ${ }^{5,1}$, María Martinón-Torres ${ }^{1,2}$, Yann Heuzé6, Eudald Carbonell ${ }^{7,8}$, Juan Luis Arsuaga ${ }^{9,10}$, M. Christopher Dean ${ }^{11,12}$, and José María Bermúdez de Castro ${ }^{1,2}$

${ }^{1}$ Centro Nacional de Investigación sobre la Evolución Humana (CENIEH), Paseo Sierra de Atapuerca 3, 09002, Burgos, Spain

2 Department of Anthropology, University College London, London, WC1H 0BW, UK

3 Equipo Primeros Pobladores de Extremadura, Casa de Cultura Rodríguez Moñino, Cáceres, Spain

4 Laboratorio de Evolución Humana, Universidad de Burgos, Edificio I+D+i, Burgos, Spain

5 University of Bordeaux, CNRS, MCC, PACE, UMR 5199 F_33615, Pessac Cedex, France

6 University of Bordeaux, UMR 5199 PACEA, Bordeaux Archaeological Sciences Cluster of Excellence, Université de Bordeaux, Pessac Cedexm, France

${ }^{7}$ Institut Català de Paleoecologia Humana i Evolució Social (IPHES), Zona Educacional 4, Campus Sescelades, Edifici W3, Universitat Rovira i Virgili, Tarragona, Spain

8 Àrea de Prehistòria, Universitat Rovira i Virgili, Avinguda de Catalunya 35, 43002, Tarragona, Spain

${ }^{9}$ Centro mixto UCM-ISCIII de Evolución y Comportamiento humanos, Madrid, Spain

10 Departamento de Geodinámica, Estratigrafía y Paleontología, Facultad de Ciencias Geológicas, Universidad Complutense de Madrid, Spain

11 Centre for Human Evolution Research (CHER), Department of Earth Sciences, Natural History Museum, London, SW7 5BD, UK

12 Department of Cell and Developmental Biology, University College London, Gower Street, London, WC1E 6BT, UK

${ }^{\square}$ Correspondence: Mario Modesto-Mata <paleomariomm@gmail.com>

* These authors contributed equally in the manuscript 


\section{Abstract}

The Bayesian statistical approach considers teeth as forming a developmental module, as opposed to a tooth-by-tooth analysis. This approach has been employed to analyze Upper Pleistocene hominins, including Neandertals and some anatomically modern humans, but never earlier populations. Here we show its application on five hominins from the TD6.2 level of the Gran Dolina site (Homo antecessor, Early Pleistocene) and the Sima de los Huesos site (Middle Pleistocene) of the Sierra de Atapuerca (Burgos, northern Spain). Our results show an advanced development of the third molars in both populations with respect to modern Homo sapiens. In addition, the Sima de los Huesos hominins differ from $H$. sapiens and $H$. antecessor in the relatively advanced development of their second molar. The relative mineralization of I1/M1 in H. antecessor appears to be similar to that of modern humans, as opposed to that of Neandertals, which appear to be unique. These observations, combined with reduced enamel formation times and the advanced development of the third molars, appear to indicate a shorter ontogenetic period in the hominins from Gran Dolina and Sima de los Huesos in comparison to modern human average.

\section{Introduction}

This study examines relative dental development in two important samples of Lower and Middle Pleistocene humans, from Gran Dolina and Sima de los Huesos (Atapuerca, Burgos, Spain). Previous work showed that these samples presented on average, enamel formation time $27 \%$ faster than in modern humans (Modesto-Mata et al., 2020). While this finding may suggest a faster overall biological clock in these earlier hominins, the sequence of tooth formation is also relevant to reconstruct life history of these hominins.

The variation in the sequence of dental maturation has been investigated between pairs of teeth (Tompkins, $1996 \mathrm{a}$; b) or taking into account the chronological ages (Smith, 1986). However, the study of the entire dentition rather than single or pairs of teeth provides a more complete picture of the dental development of an individual. One approach to investigating the sequence of dental maturation is to adopt a probabilistic approach using all teeth. Braga and Heuze (2007) proposed an analytical approach using Bayesian statistics to quantify variability in sequences of key events during tooth mineralization, independent of chronological age. This method considers the tooth within the mineralization sequence as a series of dependent units, growing within a developmental and hierarchical module. A statistical probability is determined for the likelihood of a particular dental mineralization sequence (DMS) to be present within known modern human variation. The modular system of dental development (Raff, 1996) presents the following features: 1) dental development presents an autonomous, genetically discrete organization, 2) the modular system of dental development is formed by hierarchical units, 3) dental modules have a physical place within the developing system, 4) the degree of connectivity between dental modules occurs at different levels, and 5) dental development displays temporal transformations. Overall, the variability in the patterns or DMSs is 
relevant in human evolution, as these processes allow to assess possible foundation for morphological changes (Braga and Heuze, 2007).

This approach has been recently applied to Neandertals (Bayle et al., 2009 a; Quam et al., 2015), to an Upper Paleolithic specimen from La Madeleine (Bayle et al., $2009 \mathrm{~b}$ ), and to the Lagar Velho individual (Bayle et al., 2010), a possible Neandertal-H. sapiens hybrid (Duarte et al., 1999). Remarkably, both Neandertals and the Lagar Velho specimen showed a DMS that is not known to exist in modern human variation, whereas the La Madeleine individual presented a DMS that falls within the known variation of modern H. sapiens. Moreover, the pattern of dental development of the Lagar Velho specimen is only present within the Neandertal variation. Overall, Neandertals show a proportionally advanced stage of mineralization of the first molar in comparison to their proportionally delayed stages of mineralization of the incisors. Interestingly, this statistical approach has rarely been applied to hominins older than Neandertals. Therefore, the Atapuerca hominins may give some clues on the changes of the pattern of dental development on earlier stages of human evolution.

The two archaeological sites from Atapuerca included in this study are Gran Dolina and Sima de los Huesos. Level TD6.2 of the Gran Dolina site ( 0.9-0.8 Ma) contains more than 160 human fossil remains representing at least 8 individuals attributed to the species Homo antecessor (Moreno et al., 2015; Bermúdez-de-Castro et al., 2017; Duval et al., 2018). Sima de los Huesos (SH) ( $\sim 0.43 \mathrm{Ma})$ contains more than 7000 human fossils attributed to at least 29 individuals (Bermúdez de Castro et al., 2021) whose genetic and morphological data strongly suggest they belong in the Neandertal clade (Arsuaga et al., 2014).

Previous studies attempted to evaluate the patterns of dental maturation from these two fossil populations by treating tooth types as independent units. The information provided by the study of three hominins from the Gran Dolina site (Bermúdez de Castro et al., 1999; Bermúdez de Castro et al., 2010) indicated relatively advanced calcification in the M3 compared to the M1. Hominin XVIII from the Sima de los Huesos site (Fig. 1) displayed a relatively delayed development of the lower and upper canines, a more advanced development of the lower second molars, and notably advanced development in the upper and lower third molars (Bermúdez de Castro and Rosas, 2001). Bermúdez de Castro and Rosas (2001) analyzed dental development with a non-Bayesian frame. However, this specimen was studied under this Bayesian analysis (Bayle, 2008) using the modern human samples in Braga and Heuze (2007), showing that there were not differences in regard to modern humans. In our study we apply the Bayesian statistical analysis for the complete permanent dentition of hominin XVIII, including M3s.

Here, we present a Bayesian analysis of the relative dental development of five hominins from Gran Dolina and Sima de los Huesos. We aim to test the null hypothesis that DMSs of Atapuerca hominins are found within the range of modern humans, although they may present a more advanced molar development than our species. This study complements the one published recently on the methods of analyzing the absolute timing and pattern of lateral enamel formation (Modesto-Mata et al., 2020). The results are compared with published data on Neandertals, to identify similarities or differences in the DMSs that might shed light about potential taxonomic signals. 


\section{Materials and Methods}

\section{Materials}

The specimens analysed in this paper include two individuals from Sima de los Huesos-SH (XVIII and XXV) and three individuals of $H$. antecessor (H1, H3 and H11) from Gran DolinaTD6.2 (Supplementary Table 1 and Supplementary Table 2, respectively). The criteria to determine that isolated teeth, either from Gran Dolina or Sima de los Huesos specimens, belonged to specific individuals is detailed in Bermúdez de Castro et al. (2021).

The complete permanent dentition ( 32 teeth) and the four deciduous second molars are present in hominin XVIII (Fig. 1). Hominin XXV includes a complete permanent lower dentition (16 teeth) and two deciduous second molars (Supplementary Fig. 1). All of the teeth from SH were isolated finds. The dentitions of the hominins from Gran Dolina are incomplete. H1 is composed of 16 upper and lower teeth (Supplementary Fig. 2), whereas H3 is composed of 9 upper teeth (Supplementary Fig. 3) .

The mineralization stages of the H. antecessor and Sima de los Huesos teeth were obtained by analyzing high-quality photographs of the fossils, along with 3D volume renderings from micro-CT scans. The developmental stages of the permanent dentition of fossil hominins were scored from A to H (Demirjian et al., 1973), while deciduous dentition was scored from A to H2 (Liversidge and Molleson, 2004). The teeth and mineralization stages of the TD6.2 hominins and the SH specimens are presented in Table 1. Tooth mineralization stages of fossil hominins were identified independently by three co-authors (RG-G, YQ, MMM). Discrepancies appeared in less than $4 \%$ of the teeth, and they were present over the latest stages of development of the root. In order to increase the utility of these data for other researchers who may want to reanalyze by using the Moorrees et al. (1963) scoring system, we also provide these scores in Supplementary Table 3.

When establishing the mineralization stages of the TD6.2 hominin H11 (Bermúdez de Castro et al., 2010), a new undocumented tooth situated in its alveolus has been identified by using the micro-CT. This new tooth in the TD6.2 fossil hypodigm is the lower right fourth premolar of the hominin H11 mandible. This tooth is only represented by the initial formation stage of the buccal cusp enamel (Supplementary Fig. 4). Its uncompleted mesiodistal diameter measures $\sim 3.4 \mathrm{~mm}$.

\section{Modern Human Reference Samples}

Because our fossil sample includes individuals with only permanent teeth (only mandibular, only maxillary, or both), and other individuals with a mixed dentition (Table 1 ), it was necessary to use different comparative samples to perform different comparisons.

\section{Burgos mandibular I: permanent mandibular dentition without M3}

The first comparative sample is called "Burgos mandibular I" which was drawn from three different subsets and consists of DMSs of mandibular teeth except M3. The third molar was excluded of this sample due to the tempo of development of this tooth, as it is highly 
variable among modern populations with a high frequency of agenesis. Thus, in a first attempt, we did not include the developmental stage of M3 in the DMSs in order to avoid confounding findings due to this effect.

The first subset is composed of 415 cross-sectional standardized orthopantomographs of Spanish children between 4 and 16 years old. These orthopantomographs were chosen from patients attending to different dental clinics to diagnostic and treatment. The inclusion criteria were the following: a) availability of panoramic radiographs with high clarity and good contrast, b) no systemic diseases or craniofacial anomalities, c) normal dental conditions (e.g. no hypodontia, gross pathology and missing mandibular permanent teeth except third molar) and d) no previous orthodontic treatment. The developmental stages of the different teeth were assesed following the system developed by Demirjian et al. (1973). They were first scored by YQ and thus, independently validated by RG-G.

The second subset was derived from the data included in the Electronic Encyclopedia on Maxillo-Facial, Dental and Skeletal Development (Demirjian, 1996). These data, whose developmental stages were scored by the same author, come from a longitudinal study of French-Canadian orthopantomographs of children in Montreal, conducted in the 1960s and 1970s. A total of 494 radiographs were utilized from this collection. The inclusion criteria for these radiographs was that at least one tooth was developing.

The third subset was selected from a sample of 75 mandibles of subadult individuals from a medieval archaeological population excavated in the Dominican Monastery of San Pablo (Adán-Álvarez, 2003) that are now housed at the Laboratory of Human Evolution of the University of Burgos. These specimens were scanned using a YXLON Compact (YXLON International X-Ray GmbH, Hamburg, Germany) industrial multislice computedtomography (CT) scanner, located at the University of Burgos. The mandibles were aligned along the long axis of the right mandible corpus. Scanner energy was set at $160 \mathrm{KV}$ and 4 $\mathrm{mA}$ and the field of view was between 111.1 and $187.5 \mathrm{~mm}$ to encompass the entire mandibles. The Mimics ${ }^{\mathrm{TM}}$ (Materialise, Belgium) software program was used to visualize the CT images and make the virtual reconstructions. In this sample, the inclusion criteria for these mandibles were that they preserved seven permanent teeth (from I1 to M2) and that at least one of them was developing. In this way, the final sample is composed of 32 mandibles. In this sample, developmental stages of each tooth were scored by RG-G.

\section{Burgos mandibular II: permanent mandibular dentition with M3}

The second comparative sample is called "Burgos mandibular II" and consist of 462 crosssectional standardized orthopantomographs of Spanish children in which at least M3 was developing. All the previous 415 cross-sectional orthopantomographs from the first subset of "Burgos mandibular I" are included in this comparative sample. This sample was used to explore the effect of the calcification status of this tooth in the differences and analogies between DMSs of fossil and modern humans. As in the case of "Burgos mandibular I," the developmental stages of the different teeth were first scored by YQ and thus, independently validated by RG-G. 


\section{Burgos mandibular III: permanent and deciduous teeth}

The third comparative sample is denoted as "Burgos mandibular III" and consists of 24 CTscans from San Pablo collection in which both permanent and deciduous teeth were preserved. The total sample consist of 24 individuals.

\section{Burgos maxillar}

The fourth comparative sample, called "Burgos maxillar" consist of 380 orthopantomographs of maxillary teeth chosen from patients attending to different dental clinics to diagnostic and treatment. The inclusion criteria and assessment of the developmental stages of each tooth were performed in the same way that "Burgos mandibular I." This sample was used in comparison of DMSs of fossil specimens with upper dentition preserved. More especifically, it was used to compare with hominin XVIII from Sima de los Huesos and hominins H1 and H3 from Gran Dolina-TD6.2.

\section{Bordeaux sample}

All the above samples consist of European or European origin populations. Studies comparing African-derived versus European-derived populations have shown differences in the relative calcification of several teeth (Tompkins, 1996 a). Thus, differences between DMSs of fossil specimens and our reference sample, do not necessarily imply that these DMSs are unique of fossil specimens. Taking this into account, in those cases in which we detected differences between DMSs of TD6 and SH individuals and our reference sample, we performed an additional comparison of these fossils with other modern human sample. To do that, we used a sample from the University of Bordeaux that consists of 2387 children (1346 girls and 1041 boys) aged from 2 to 16 years. Their geographic origins include Southern France, Iran and the Ivory Coast (see Braga and Heuze (2007) for further details). This reference sample is based on cross-sectional standardized panoramic radiographs of teeth, and children selected were clinically free of anomalies in tooth number, size or shape. Only lower teeth were scored (from I1 to M2), thus, we have only been able to make comparisons between this sample and Sima de los Huesos specimens with lower dentition.

Despite these modern human samples are relatively large, we acknowledge that more samples from larger geographic areas and temporal frames should be taken into consideration to have an overall perspective of modern human variation.

\section{Bayesian Statistical Approach}

The comparison of the DMSs in the H. antecessor sample, the Sima de los Huesos hominins, and the samples of modern humans was performed using a Bayesian statistical approach (Braga et al., 2005; Braga and Heuze, 2007), which produces a probability indicating the likelihood that the developmental pattern of a fossil individual may be found within the variation of the modern human population. The underlying hypothesis is that any DMS represents a developmental module. This DMS is composed of hierarchical units, which show varying degrees of interaction. The teeth are, therefore considered as statistically dependent units in the Bayes's rule of conditional probability. As stated previously, the 
Bayesian approach integrates the concept of modularity, as opposed to tooth-by-tooth analysis (Braga and Heuze, 2007).

The interactions between teeth can be measured by deconstructing the original DMS into two subsets with no shared elements. Following this approach, each DMS was separated into a finite number of combinations that correspond to the conditional probabilities of observing one or more teeth at a certain developmental stage (subset_1) conditioned on the attained developmental status of the remaining teeth (subset_2) (Braga and Heuze, 2007). This probability can be expressed as follows:

$\mathrm{P}($ subset_1 | subset_2 $)=\mathrm{P}($ subset_2 | subset_1) * Pprior(subset_1) / [P(subset_2 | subset_1) * Pprior(subset_1)] + [P(subset_2 | subset $\neq 1) *$ Pprior(subset $\neq 1)]$

where:

- $\quad \mathrm{P}($ subset_2 | subset_1) is the observed proportion of individuals in the reference samples showing the DMS corresponding to the subset_2 given the DMS corresponding to the subset_1.

- $\quad \mathrm{P}($ subset_2 subset $\neq 1$ ) is the observed proportion of individuals in the reference samples showing the DMS corresponding to the subset_2 given a DMS different to that of subset_1.

- $\quad$ Pprior(subset_1) is the probability that the DMS corresponding to the subset_1 may be found within the references samples.

- $\quad$ Pprior(subset $\neq 1$ ) is the probability that the DMS is different to that of the subset_1 may be found within the references samples.

As can be seen in this formula, the posterior probabilities depends on the prior probabilities. These prior probabilities can be calculated as the relative frequencies of this subset_1 in our reference sample. In this way, we were assuming that our reference samples priors are representative of the fossil individuals. However, the references samples were constructed by "availability sampling." It implies that our reference samples exhibit biased distributions of the different dental maturity stages. Thus, posterior probabilities derived this way will tend to over or underestimate in the fossil individuals. In these cases, the best option is to choose priors by using external knowledge independent of the data (Couvreur et al., 2010). Thus, we have two options to estimate priors: either use demographic data or to assume an unbiased and uniform frequency distribution of the different developmental stages of each teeth (Braga and Heuze, 2007). In this case, we selected the second option, since the posterior probabilities of the different DMSs of fossil specimens will be estimated independent of the distribution of the dental maturity stages in the reference samples used in this study (Konigsberg and Frankenberg, 1992).

Another question related to the Bayesian analysis is that there may be no observations for "subset 2" that are the same as for the fossils. This, in turn, give division by zero. In these cases the particular posterior probabilities have been dropped. For this reasons, we depicted in each case the number of posterior probabilities that could have been calculated. 
In addition, we have also calculated the number of times in which the exact fossil sequence appears in the reference sample.

Probabilities were classified based on the thresholds of $p<0.25$ and $p>0.75$. While values of 0.25 and 0.75 does not represent an absolute cutoff in a continuous probability distribution ranging from 0 to 1 , in Bayesian approaches they represent a threshold to assess the likelihood of different events (Braga and Heuze, 2007). In this way, probabilities lower than 0.25 indicate very unlike events, probabilities greater than 0.75 represent very likely events and probabilities between 0.25 and 0.75 are more likely associated to random events.

\section{Results}

DMSs from H. antecessor from Gran Dolina and the Sima de los Huesos hominins are displayed in Table 1 . The H. antecessor individual H11 is the least mature of the TD6.2 sample. Hominin $\mathrm{H} 1$ is the most mature individual within the H. antecessor hypodigm, and hominin $\mathrm{H} 3$ has an intermediate state of dental maturity. The individuals XVIII and XXV from Sima de los Huesos have completely formed incisors and first molars, with premolars and second and third molars that are still developing. Hominin XVIII is slightly less mature than hominin XXV, as the former's developing teeth are in an earlier mineralization stage. In fact, the canine roots of the XVIII hominin were still forming when this individual died.

\section{Dental development of $\boldsymbol{H}$. antecessor}

Table 2 shows the distribution of probabilities that the DMSs of these fossil specimens falls within our reference sample from Burgos. The hominin $\mathrm{H} 11$ of $H$. antecessor displays the highest probabilities that its DMS falls within the modern human range, when deciduous teeth are both incorporated or excluded, with values above 0.95 (Fig. 2). In the case of H1, which has both lower and upper dentition preserved, the probabilities, when the M3 is excluded, are between 0.73 and 0.83 respectively. However, when the M3 is incorporated in the analysis, the probability of the upper dentition decreases to 0.60 , although the probability of the lower dentition is barely altered. The probability of the upper dentition sequence of the $\mathrm{H} 3$ specimen when the M3 is excluded is 0.85 . However, when the M3 is included, the probability is 0 , as this specific pattern of DMS is not present in the modern human sample.

Within our reference sample the most frequent dental maturational sequence is that showed by $\mathrm{H} 1$ lower dentition (excluding M3), and the less frequent is that showed by $\mathrm{H} 3$ upper dentition (including M3). They were found 69 and zero times, respectively (7.44\% and $0 \%$ with respect to the total DMSs, respectively).

\section{Dental development of Sima de los Huesos hominins}

Regarding Sima de los Huesos individuals, within our reference sample the maturational sequences of hominin XVIII upper and lower dentition are found 1 and 11 times respectively ( $0.21 \%$ and $1.19 \%$ with respect to the total DMSs, respectively) Table 2 . For 
the upper dentition this sequence is found in one male aged 8 years. In the case of the mandibular dentition, we found this DMS in six females aged between seven and nine years and in five males aged between seven and ten years. Interestingly, none of these modern individuals show at the same time the maxillar and mandibular maturational sequence than hominin XVIII. The DMS of hominin XXV is found one time in our reference simple, in one male aged 11 years.

The probabilities of the upper and lower dentitions of the Sima de los Huesos hominins XVIII and XXV (Fig. 3) when the M3 is included are 0, for the same reason stated above. Interestingly, when M3 is removed, the DMS of SH specimens are compared with Burgos's sample, most of probabilities are lower than 0.25 . Thus, we can assume that the DMSs showed by hominins XVIII and XXV are unlikely to occur is in this sample.

Nonetheless, when DMSs of SH individuals are compared with Bordeaux's sample, most of probabilities are higher or equal 0.75 (Fig. 3), namely, these sequences are likely in this sample. These differences may be related to inter-populational differences in dental development in Homo sapiens. Based on this, we cannot discard that hominins from SH present a pattern of development similar to that of Homo sapiens.

However, in some combinations the probabilities showed by hominins from SH are lower than 0.25 relative to both modern samples. In the case of hominin XVIII these combinations correspond to the following conditional probabilities: I1I2M1 if CP3P4M2 and CP3P4M2 if I1I2M1. For the hominin XXV these conditional probabilities are: CM2 if I1I2P3P4M1, P3P4 if I1 I2CM1M2, I1I2CM1M2 if P3P4 and I1I2P3P4M1 if CM2. Therefore, in these sequences the developmental status of one or some teeth deviate significantly from those observed in our two reference samples. We did not observe probabilities lower than 0.25 in the combinations corresponding to the developmental status of each of these teeth taken separately versus the others. Thus, we concluded that none of these teeth separately show an abnormal developmental status in these hominins from $\mathrm{SH}$.

In the case of hominin XVIII, the more informative DMS is I1I2M1 if CP3P4M2, since this specimen showed I1, I2 and M1 completely formed. When we fixed in our "Burgos mandibular I" sample the sequence C=F, P3=E, P4=E and M2=E, the developmental stages of I2 and M2 are more delayed. More precisely, a 64\% of individulas showed the I2 and M2, respectively, in a developmental stage $\mathrm{F}$ or $\mathrm{G}$. This could point to a relative advancement of development of 12 and M2 in this SH specimen.

In the case of hominin XXV, the analysis of sequences CM2 if I1I2P3P4M1 and I1I2P3P4M1 if $C M 2$, point to a relative advance in the developmental status of canine and second molar. If we fixed in our "Burgos mandibular I" sample the developmental stages of P3 and P4 as F, a $88 \%$ of individuals showed the canine and second mandibular in stages of development more delayed than XXV hominin. The developmental stages of I1, I2 and M1 are equal in our comparative sample then in hominin XXV.

In the other way, the analysis of sequences P3P4 if I1 I2CM1M2 and I1I2CM1M2 if P3P4 show that P3 and $\mathrm{P} 4$ are relatively more advanced in our comparative sample. Fixing the developmental stages of I1, I2, C, M1 and M2 a 82\% of individulas within our comparative sample showed a developmental stage H or G. 
Thus, it seems that SH hominins could be characterized by a relative advancement of development of M1 and M2 and/or a relative delay in the development of both premolars.

\section{Discussion and Conclusion}

This study represents the first attempt to apply a Bayesian statistical approach to quantify DMS variation in fossil populations older than Neandertals. Here, we used this method on two extinct hominin populations from the Early and Middle Pleistocene sites at Atapuerca (Spain).

In H. antecessor, the DMS of hominin $\mathrm{H} 1$ has a high range of probabilities of belonging to a modern human population. However, the DMS of this hominin shows fully developed incisors, canines, premolars and first molars, all at stage $\mathrm{H}$ (Table 1). This prevents the evaluation of differences between anterior and posterior teeth during development, as well as the comparison of the developmental pattern with that of modern humans. The high probabilities compared to modern humans are due principally to the relative development of the second and third molars, which are still forming. It is also very likely that the DMS of the hominin $\mathrm{H} 11$ of the same population, which has the permanent dentition from the I1 to the M1, including the two deciduous molars, is within modern human variation. However, as M2 and M3 are not preserved in this specimen, the comparison between anteriorposterior dichotomy also remains incomplete. Finally, H. antecessor $\mathrm{H} 3$ does present anterior and posterior teeth that are still forming. In this case, the probabilities vary from 0 to 0.85 depending on the inclusion or exclusion of the M3, respectively. In this regard, $H$. antecessor $\mathrm{H} 3$ suffered from a unilateral impactation of the M2 as a result of the ectopic position of the developing M3, likely due to the lack of space in the maxilla (Martín-Francés et al., 2020). However, it has been documented that there exist significant differences in root growth between unilateral impacted and non-impacted mandibular M2s coming from modern Israelis and Chinese-Americans (Shapira et al., 2011). By expanding these results to their maxillary counterparts, our analysis should be taken with some caution. Anyhow, the relative dental development of the M3 in H. antecessor appears to be developmentally advanced in relation to the M1 and M2 when they are compared with modern humans.

Overall, $H$. antecessor dental development follows modern human patterns when looking at only anterior or posterior teeth separately, and when M3 is excluded. When both regions are compared, the M3 is advanced in its mineralization in respect to modern humans. However the relative development of I1 and M1 fit within the range of modern humans, which corresponds with previous observations (Bermúdez de Castro et al., 1999; Bermúdez de Castro et al., 2010).

In respect to the hominins from the Sima de los Huesos site, different probabilities are produced, depending on the modern sample used for comparison, and on the presence of M3 in the analyses. The DMSs do not correspond to either modern human sample when the M3 is included, indicating that this tooth is advanced in its relative development when compared to modern humans. When the M3 is removed, the probabilities vary depending on which reference sample of modern humans is used for comparison. 
The inclusion or exclusion of third molars in the Bayesian analyses offered different probabilities of $H$. antecessor and Sima de los Huesos hominins to be grouped with modern humans. It is known that mandibular third molars are highly variable in their timing of maturation in modern humans (Liversidge, 2008), and they also have the highest frequency of polymorphism, malposition, impactation and agenesis (Nanda, 1954; Garn et al., 1963; Anderson et al., 1975; Bermúdez de Castro, 1989). Moreover, statistical differences within modern humans were found in the delay of M3 formation in Caucasian children from both London and Cape Town in comparison to black South African children (Liversidge, 2008). This delay is also present in a French-Canadian population compared to black South Africans, in both the second and third molars (Tompkins, 1996 a).

In this regard, the delay of molar formation in non-black Africans compared to black Africans might be responsible for the different probabilities observed in the Sima de los Huesos lower dentition when their mineralization sequences are compared with modern human variation. The sample from the University of Bordeaux includes individuals of black sub-Saharan provenance (Ivory Coast), whereas the sample from Univerity of Burgos does not include any. This may be the reason for the apparent similarity between the Burgos sample and the Sima de los Huesos individuals, and the apparently advanced lower molar developmental sequences of the ancient individuals in comparison to the Bordeaux sample. As the Burgos sample was used when calculating the probabilities in H. antecessor and the hominins from Sima de los Huesos when the M3 is removed, the fact that the Early Pleistocene population has higher probabilities than the Middle Pleistocene indicates that the M2 is relatively advanced in its development in the Sima de los Huesos individuals, as it was previously postulated for the XVIII specimen (Bermúdez de Castro and Rosas, 2001).

It is remarkable the pattern of development between upper and lower third molars. For instance, it has been observed in a sample of white Americans that the formation of maxillary M3s was slightly advanced in comparison to the mandibular M3s (Mincer et al., 1993). However, this pattern is not shared in either the Sima de los Huesos hominins or the sample of $H$. antecessor. Both M3s of hominin H1 of the Gran Dolina-TD6.2 site are at the same stage of mineralization (C), whereas the maxillary M3 of the hominin XVIII from Sima de los Huesos is delayed in its formation in comparison to the mandibular M3 (B and C, respectively). This fact could be key to differentiate European Lower and Middle Pleistocene hominins among them and also in respect with modern humans.

Leaving aside the analysis of third molars on their own, the lower first and second molars of both the H. antecessor $\mathrm{H} 1$ and the hominin XXV of Sima de los Huesos are at stages $\mathrm{H}$ and $G$, respectively (Table 1). Differences between the hominins from these sites emerge when the premolars and third molars are considered. Premolars in the hominin XXV from Sima de los Huesos are developmentally delayed in comparison to hominin $\mathrm{H} 1$ of $H$. antecessor (stages F-F and $\mathrm{H}-\mathrm{H}$, respectively). The third molar, however, is developmentally advanced in XXV in comparison to hominin H1 (stages D and C, respectively). Caucasian FrenchCanadian, Native American and black African modern human samples do not display differences in their relative premolar calcification across these three groups (Tompkins, 1996 a), so differences observed in both Pleistocene hominins could be explained by a taxonomic signal. Taking into account third premolars, it was stated that P3 in Neandertals 
was delayed in comparison to modern humans (Tompkins, 1996 b), whereas in Sima de los Huesos hominins both premolars appear to be delayed.

Neandertals are key to be used as comparison to H. antecessor and Sima de los Huesos, not only because they share the same geographical area, but also because typical Neandertal features were identified in both human populations at Atapuerca Bermúdez-de-Castro et al. (2017). Following the Bayesian statistical approach, Neandertals display probability values that exclude them from belonging to modern humans, as shown in the Roc de Marsal (Bayle et al., 2009 c) and the Cova del Gegant (Quam et al., 2015) specimens. The Cova del Gegant individual is dated in $52.3 \pm 2.3 \mathrm{ka}$ (Daura et al., 2010), whereas the Roc de Marsal Neandertal is located most probably between 60 and $70 \mathrm{ka}$ (Guérin et al., 2012). In both cases, the Bayesian probability is zero, which means that their DMSs are not present in the modern human reference samples employed. In addition, the Roc de Marsal child has a relatively advanced stage of mineralization of the first molar in respect to the comparatively delayed maturation levels of its incisors (Bayle et al., 2009 c). Bearing in mind that the relative development of I1 and M1 in H. antecessor, and likely that of the Sima de los Huesos hominins, is within modern human variation, this asynchrony in the Neandertals I1/M1 relative development could be interpreted as exclusive to $H$. neanderthalensis. Although this observation was made only on the Roc de Marsal Neandertal, a claim for caution is made, as this feature could be key to differentiating Upper Pleistocene Neandertals from their ancestors in the European Middle Pleistocene. Interestingly, the Neandertal specimen Spy VI, represented only by four deciduous teeth (lower i1, i2, c; and upper i1), shows a Bayesian probability above 0.75 in respect to modern humans (Crevecoeur et al., 2010). However, this high probability is expected as it is only based on deciduous incisors and one canine, therefore, only anterior teeth and not anterior vs posterior dentition. Finally, The Lagar Velho 1 child, a potential hybrid specimen between Neandertals and anatomically modern humans, with an age of $\sim 24.5 \mathrm{ka}$ B.P. (Duarte et al., 1999), also presents a dental maturation pattern not represented in the modern human variation (Bayle et al., 2010).

It is remarkable that the relative relationships between anterior and posterior teeth were found to be responsible for differences in extinct hominins (Tompkins, $1996 \mathrm{~b}$ ). This could explain why Neandertals that preserve both types of teeth and the Lagar Velho specimen have a pattern of dental development not present in modern humans, whereas Spy VI, only represented by anterior dentition, shows higher probabilities. In contrast, the Upper Paleolithic child from La Madeleine (LM4), a fully anatomically modern human child with an age of 10,190 \pm 100 years (Gambier et al., 2000), shows comparatively higher probabilities of belonging to modern humans (Bayle et al., 2009 b). In particular, 30\% of LM4 DMSs probabilities are superior to 0.75 , and $70 \%$ fall between 0.25 and 0.75 .

El Sidrón J1 Neandertal preserves the permanent dentition from I1 to M2 and some deciduous teeth (Rosas et al., 2017). Only the M3 crypt is present so that its relative stage of mineralization with respect to the modern human sample employed in this study remains unknown. However, the DMS of this specimen is not found in any of the 10901 modern humans radiographs used to calculate probability density plots. From a nonBayesian approach, probability density plots for mean age of transition entering each individual permanent tooth stage indicate that El Sidrón J1 fell within the modern human 
range (Rosas et al., 2017). However, premolar and molar plots show slightly older, advanced, ages than anterior dentition plots in respect to the modern human sample, although a high degree of overlap exists among both fields.

H. antecessor hominin H3 has an upper M2 at stage D as does El Sidrón lower M2. However, the upper M3 is already at stage B in H3 but is not yet mineralizing in El Sidrón. Similarly, SH XVIII M2 and M3 are just two developmental stages apart (E and C) while M2 and M3 in El Sidrón are at least four stages apart (M2 stage D, M3 crypt only present). This all suggests a Neandertal DMS distinct from modern humans as well as greater advancement of M3 relative to M2 in TD6.2 and SH hominins than in El Sidrón. However, other Neandertal specimens reveal the likely extent of variation in M1-M2-M3 mineralization sequence. When molar formation stages in Scladina are expressed as H-F-C (in M1, M2 and M3, respectively) (Smith et al., 2010), then M2 and M3 are just two stages apart and comparable to individual XXV from Sima de los Huesos. This both fits with the range of more advanced or delayed chronological ages determined for Neandertals at various stages of development (Macchiarelli et al., 2006; Smith et al., 2010; Rosas et al., 2017) but also underscores the likely developmental overlap between the TD6.2, SH and Neandertal hominins.

It is worth mentioning that the hominins from Sima de los Huesos and H. antecessor are older in their ages-at-death than Gegant-5, Roc de Marsal 1, Lagar Velho 1 or La Madeleine 4. Although the previous comparisons are directly observed and measured, we acknowledge that the comparisons were not made in similar ages-at-death.

In a broader perspective, dental development is not only assessed by approaching the relative development of the teeth, but also by taking into account the time of formation of their dental tissues. In this regard, lateral enamel formation times of the entire dentition in both $H$. antecessor and the Sima de los Huesos hominins was $\sim 27 \%$ shorter than in modern humans (Modesto-Mata et al., 2020). Despite the high probability of some dental mineralization sequences of $H$. antecessor and Sima de los Huesos in respect to modern human variation, the fact that both populations display an advanced molar development and more rapid enamel formation times, distinguishes them from $\mathrm{H}$. sapiens.

These two different lines of evidence shed some light on the processes of growth and development in H. antecessor and the Sima de los Huesos hominins. They support a working hypothesis that both Pleistocene populations had a shorter period of general growth, ontogeny and skeletal maturation than modern human average, being placed most likely at the lower tail of modern human distribution today. Although more data are needed to further test this hypothesis, such as accurate estimations of the timing and rate of root formation, cuspal enamel formation times and ages at eruption in these hominins, some findings about skeletal development seem to confirm it. For instance, clavicular growth and development in H. antecessor is faster than in modern humans (García-González et al., 2009), a trait shared with $H$. neanderthalensis and H. ergaster. Some evidence points to a slower height growth rate in Neandertals during infancy and early childhood compared to modern humans, which would explain differences in adult height between these populations (Martín-González et al., 2012). However, this fact explains differences in the growth rate models but not in the overall timing of maturation. In modern humans, dental 
development and skeletal growth are moderately correlated and thus, individuals that are dentally advanced relative to their peers also tend to be skeletally advanced (Šešelj, 2013). Thus, if we can assume the same relationship between dental and skeletal development in $H$. antecessor, Sima de los Huesos and modern humans, these findings, along to those of this study, suggest an advanced development in H antecessor and Sima de los Huesos hominins, probably reaching adulthood at around 14-15 years of age.

In conclusion, both $H$. antecessor and the Sima de los Huesos hominins show advanced development of the M3 in comparison to modern H. sapiens. However, the Sima de los Huesos hominins appear also to show advanced development of the M2 in respect to both $H$. antecessor and modern humans. When anterior and posterior dentitions of $H$. antecessor are compared independently with modern humans, they present high probabilities of statistical variation. However, when both anterior and posterior teeth are compared synchronously, their probabilities decrease, indicating differences between the developing anterior and posterior dentitions between modern and extinct human populations. The advanced developmental sequence of M2 and M3, along with the more rapid enamel formation times, points to a shorter ontogeny in these hominins compared to modern humans.

\section{Acknowledgments}

Funding for this study comes from the Spanish Ministry of Science/FEDER, grant numbers CGL2012-38434-C03-01/02/03, CGL2014-52611-C2-1-P, CGL2015-65387-C3-2-P, CGL2015-65387-C3-3-P, PGC2018-093925-B-C31, PGC2018-093925-B-C33, HAR201455131, HAR2017-86509-P), Acción Integrada Francia-España (HF2001-0115), Consejería de Educación de la Junta de Castilla y León (CEN074A12-2), The Leakey Foundation (through the personal support of Gordon Getty 2013 and Dub Crook 2014, 2015, 2016, 2018 to author MM-T). MMP and LMF are beneficiaries of postdoctoral grants by the Atapuerca Foundation and IdEx, respectively. CG-C, MM-M and MMP were funded by doctoral grants from the European Social Fund (BOCYL-D-02102014-10 and BOCYL-D20052013-14) through the Consejería de Educación de Castilla y León (Spain) with the European Social Fund. Most of the data acquisition was performed at the Laboratory of Microscopy of the CENIEH-ICTS (Spain) in collaboration with CENIEH staff. Restoration and conservation work on the material was carried out by Pilar Fernández-Colón from the Conservation and Restoration Area of CENIEH-ICTS, Lucía López-Polín from IPHES and Maicu Ortega from the Centro de Evolución y Comportamiento Humanos UCM-ISCIII. J.M. Álverez-Tovar, M. Esteves Dias, A. Castillo Fernández and José Miguel Carretero provided the orthopantomographies of modern children. Marina Lozano, Ignacio Martínez, Cáceres Museum and Extremadura Government helped in the assessment of the scientific material. Without the persistent effort of the Atapuerca Research Team this work would have not been possible. Descriptions in the paper use the taxonomy provided by CRediT. We describe contributions to the paper using the taxonomy provided by CRediT. Conceptualization: MM-M, JMBC, MCD; Formal analysis: MM-M, RG-G, YQ; Investigation: MM-M, RG-G, YQ; Methodology: MM-M, RG-G, YQ; Resources: MCD, JMBC, EC, JLA; Software: MM-M; Supervision: JMBC, MCD; Visualization: MM-M; Writing-original draft: MM-M; 
Writing - review \& editing: MM-M, MCD, RG-G, YQ, YH, CG-C, MMP, LMF, MM-T, EC, JLA, JMBC. We are especially grateful to the referees and Associated Editor for their comments and suggestions, which have greatly improved the paper.

\section{Conflict of interest}

The authors declare no conflicts of interest.

\section{Data availability statement}

The dental mineralization sequences (DMS) of the two Pleistocene populations of Atapuerca are available in the article. Modern human DMSs may be available from Rebeca García (Burgos sample), Yuliet Quintino (Burgos sample) and Yann Heuzé (Bordeaux sample) upon reasonable request. All other data to support the findings of this study are available in the supplementary material of this article. 


\section{Tables and Figures}

Table 1: Mineralization stages of $H$. antecessor (TD6.2) and Sima de los Huesos (SH) teeth following stages defined by Demirjian et al. (1973) for permanent dentition and Liversidge and Molleson (2004) for deciduous dentition**. These stages were employed in the Bayesian statistical approach to determine whether their sequences belong to H. sapiens. brk $=$ broken.

\begin{tabular}{lllllllllllll} 
Site & Specimen & Position & I1 & I2 & C & P3 & P4 & M1 & M2 & M3 & dm1 & dm2 \\
\hline TD6 & H1 & Lower & - & H & H & H & H & H & G & C & - & - \\
\hline TD6 & H1 & Upper & - & - & H & H & - & H & G & C & - & - \\
\hline TD6 & H3 & Upper & - & G & F & E & E & H & E & B & - & - \\
\hline TD6 & H11 & Lower & D & D & C & B & A & E & - & - & H2 & H1 \\
\hline SH & XVIII & Lower & H & H & F & E & E & H & E & C & - & brk \\
\hline SH & XVIII & Upper & H & H & F & E & E & H & E & B & - & brk \\
\hline SH & XXV & Lower & H & H & H & F & F & H & G & D & - & brk \\
\hline
\end{tabular}


Table 2: Results of Bayesian analysis of the dental mineralization sequences of $H$. antecessor (TD6.2) and Sima de los Huesos (SH) hominins. Arc: arch (U, upper; L, lower); DMS: dental maturational sequence (I, DMS excluding M3; II, DMS sequence including M3; III, DMS including deciduous teeth). N: comparative sample size; NTC: number of combinations; NS: number of times the fossil DMSs are found within our modern human reference sample; NS (\%): NS expressed in percentage with this formula (NS*100)/N.

\begin{tabular}{|c|c|c|c|c|c|c|c|c|c|c|}
\hline \multirow[t]{2}{*}{ Site } & \multirow[t]{2}{*}{ Specimen } & \multirow[t]{2}{*}{ Arc } & \multirow[t]{2}{*}{ DMS } & \multirow[t]{2}{*}{$\mathbf{N}$} & \multirow[t]{2}{*}{ NTC } & \multirow[t]{2}{*}{ NS } & \multirow{2}{*}{$\begin{array}{l}\text { NS } \\
(\%)\end{array}$} & \multicolumn{3}{|c|}{ Probability balance (\%) } \\
\hline & & & & & & & & $P<0.25$ & $0.25<\mathrm{P}<0.75$ & $P>0.75$ \\
\hline \multirow[t]{8}{*}{ TD6.2 } & \multirow[t]{4}{*}{$\mathrm{H} 1$} & $\mathrm{U}$ & I & 380 & 14 & 27 & 7.11 & 0.00 & 50.00 & 50.00 \\
\hline & & $\mathrm{U}$ & II & 462 & 30 & 8 & 1.73 & 0.00 & 90.00 & 10.00 \\
\hline & & $\mathrm{L}$ & I & 928 & 62 & 69 & 7.44 & 6.45 & 24.19 & 69.35 \\
\hline & & $\mathrm{L}$ & II & 481 & 116 & 6 & 1.25 & 0.00 & 57.14 & 42.86 \\
\hline & \multirow[t]{2}{*}{$\mathrm{H} 3$} & $\mathrm{U}$ & I & 380 & 62 & 1 & 0.26 & 0.00 & 17.74 & 82.26 \\
\hline & & $\mathrm{U}$ & II & 462 & 126 & 0 & 0.00 & 100.00 & 0.00 & 0.00 \\
\hline & \multirow[t]{2}{*}{ H11 } & $\mathrm{L}$ & I & 928 & 62 & 1 & 0.11 & 0.00 & 3.23 & 96.77 \\
\hline & & $\mathrm{L}$ & III & 24 & 254 & 1 & 4.17 & 0.00 & 3.15 & 96.85 \\
\hline \multirow[t]{6}{*}{ SH } & \multirow[t]{4}{*}{ XVIII } & $\mathrm{U}$ & I & 481 & 126 & 1 & 0.21 & 48.41 & 25.40 & 26.19 \\
\hline & & U & II & 462 & 254 & 0 & 0.00 & 100.00 & 0.00 & 0.00 \\
\hline & & $\mathrm{L}$ & I & 928 & 126 & 11 & 1.19 & 63.49 & 30.15 & 6.35 \\
\hline & & $\mathrm{L}$ & II & 481 & 254 & 0 & 0.00 & 100.00 & 0.00 & 0.00 \\
\hline & \multirow[t]{2}{*}{ XXV } & $\mathrm{L}$ & I & 928 & 126 & 1 & 0.11 & 84.91 & 9.52 & 5.56 \\
\hline & & $\mathrm{L}$ & II & 481 & 254 & 1 & 0.21 & 100.00 & 0.00 & 0.00 \\
\hline
\end{tabular}


Fig. 1: Buccal view of the complete dentition of the Sima de los Huesos hominin XVIII. Top row: upper dentition; bottom row: lower dentition. dm2s are placed above the crown of their respective P4s. Top left: upper right M3; bottom right: lower left M3. Scale bar $=1 \mathrm{~cm}$.

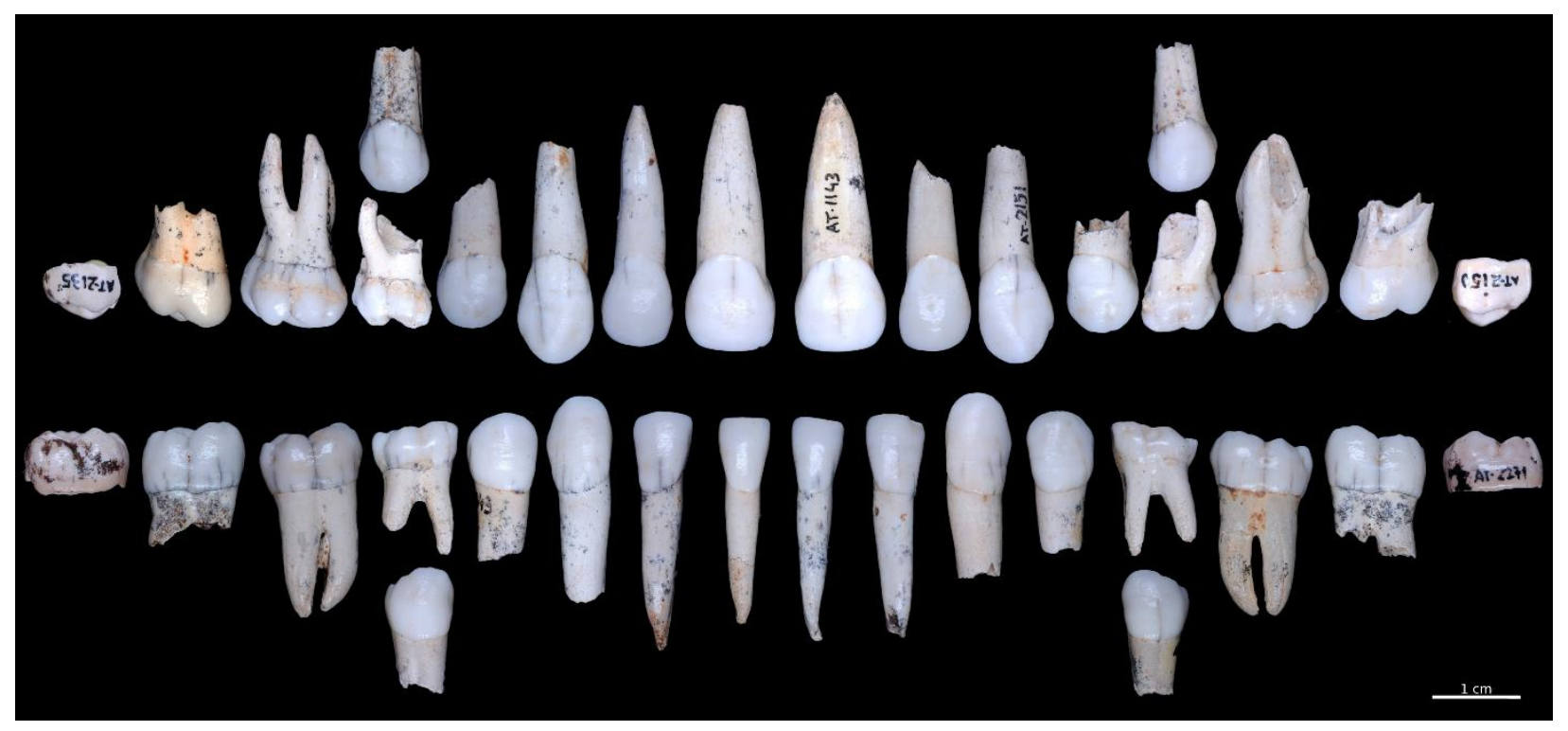


Fig. 2: Bayesian probabilities of the H. antecessor dental sequences in respect to the DMS variation in modern humans. Three hominins are depicted: H1, H3, H11. A) lower dentition of H1; B) upper dentition of H1; C) upper dentition of H3; D) lower dentition of H11. Green bar: probabilities equal to or higher than 0.75 ; red bar: probabilities equal to or lower than 0.25 . Red lines and dots: probabilities calculated by using the modern human reference sample from the University of Burgos.
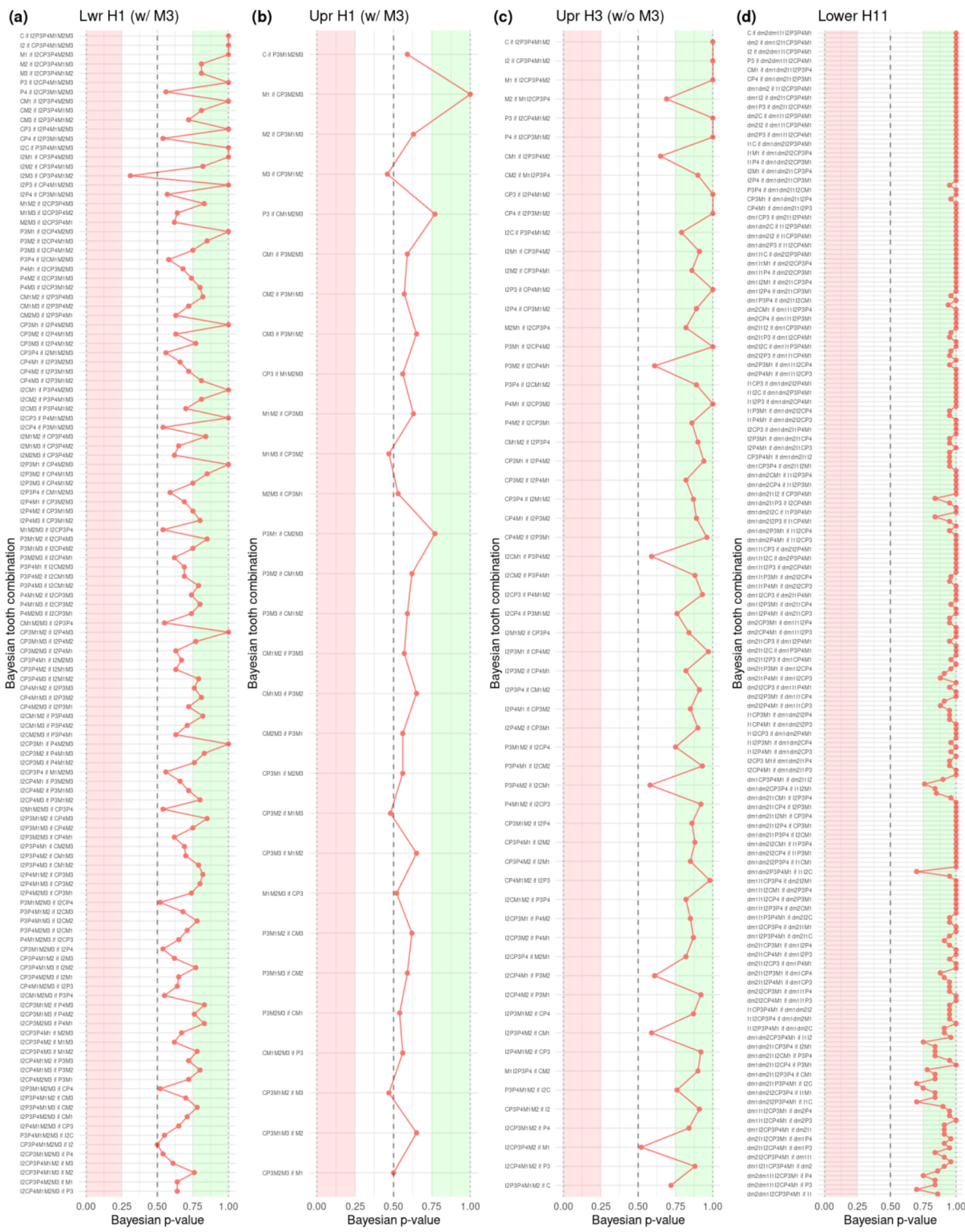
Fig. 3: Bayesian probabilities of the Sima de los Huesos (SH) dental sequences in respect to the DMS variation in modern humans. Two hominins are represented: XVIII and XXV. The M3 has not been included in the calculation of the Bayesian probabilities for both specimens. A) lower dentition of hominin XXV; B) lower dentition of hominin XVIII; C) upper dentition of hominin XVIII. Green bar: probabilities equal to or higher than 0.75; red bar: probabilities equal to or lower than 0.25 . Red lines and dots: probabilities calculated by using the modern human reference sample from the University of Burgos; blue lines and dots in respect to the reference sample from University of Bordeaux.

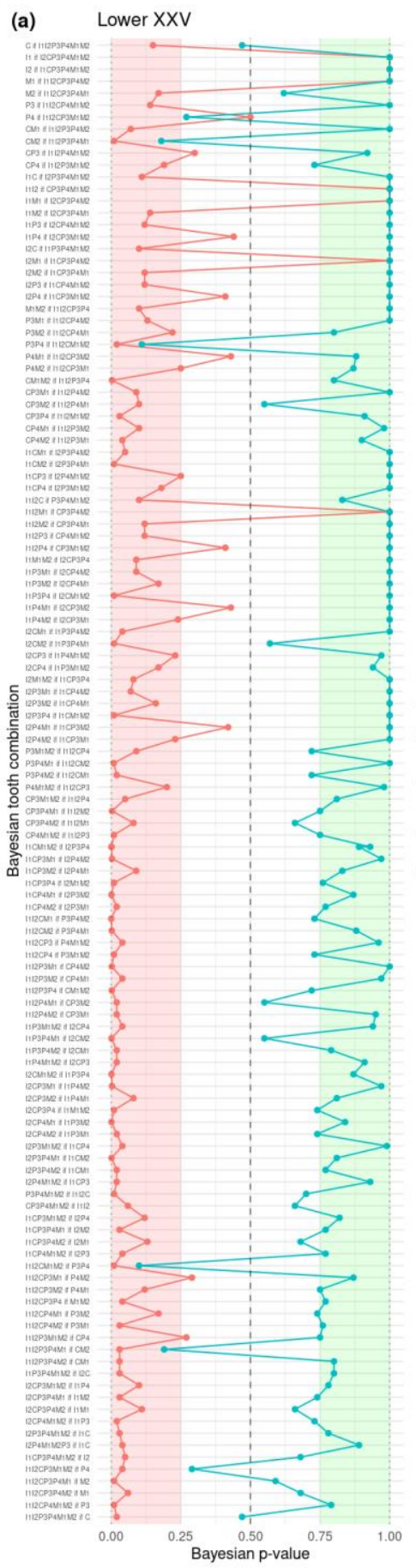

(b)

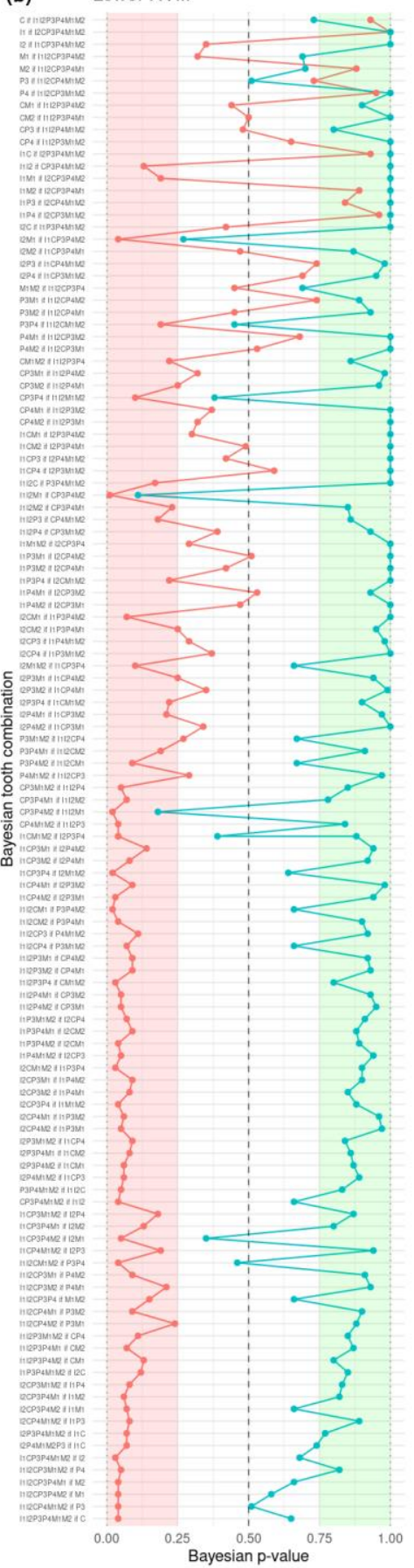

(c)

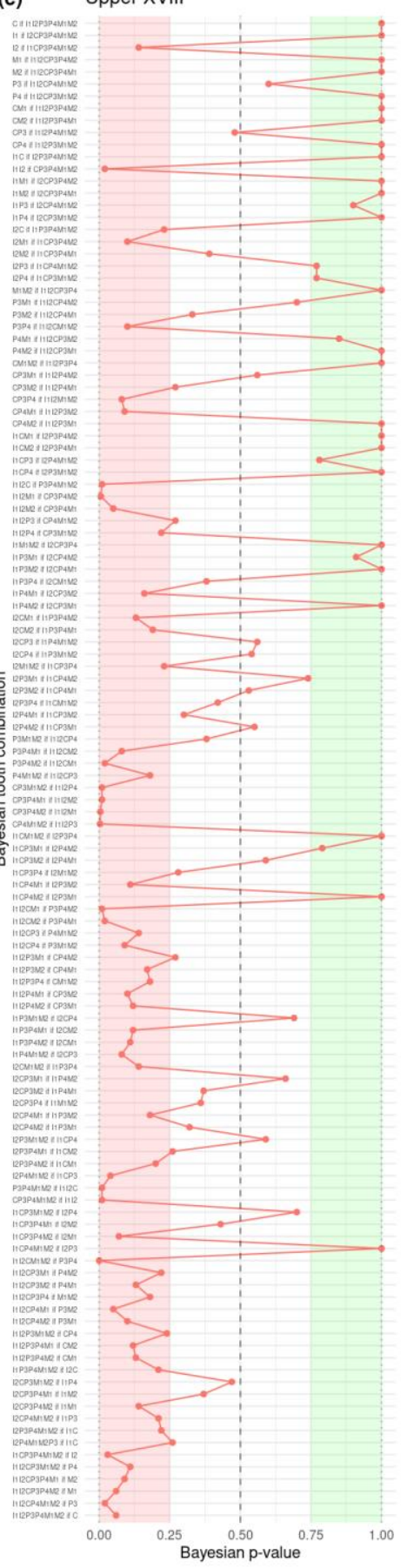




\section{References}

Adán-Álvarez GE. 2003. Memoria de la actuación arqueológica en el antiguo monasterio de San Pablo, Burgos. Valladolid: Junta de Castilla y León.

Anderson DL, Thompson GW, Popovich F. 1975. Evolutionary dental changes. American Journal of Physical Anthropology 43:95-102.

Arsuaga JL, Martínez I, Arnold LJ, Aranburu A, Gracia-Téllez A, Sharp WD, Quam RM, Falguères $C$, Pantoja-Pérez A, Bischoff J, Poza-Rey E, Parés JM, Carretero JM, Demuro $M$, Lorenzo C, Sala N, Martinón-Torres M, García N, Velasco AA de, Cuenca-Bescós G, GómezOlivencia A, Moreno D, Pablos A, Shen C-C, Rodríguez L, Ortega AI, García R, Bonmatí A, Castro JMB de, Carbonell E. 2014. Neandertal roots: Cranial and chronological evidence from Sima de los Huesos. Science 344:1358-1363.

Bayle P. 2008. Analyses quantitatives par imagerie à haute résolution des séquences de maturation dentaire et des proportions des tissus des dents déciduales chez les Néanderthaliens et les Hommes modernes. Available from: http://thesesups.upstlse.fr/563/

Bayle P, Braga J, Mazurier A, Macchiarelli R. 2009c. Dental developmental pattern of the Neanderthal child from Roc de Marsal: A high-resolution 3D analysis. Journal of Human Evolution 56:66-75.

Bayle P, Braga J, Mazurier A, Macchiarelli R. 2009b. Brief communication: High-resolution assessment of the dental developmental pattern and characterization of tooth tissue proportions in the late Upper Paleolithic child from La Madeleine, France. American Journal of Physical Anthropology [Internet] 138:493-498. Available from:

https://onlinelibrary.wiley.com/doi/abs/10.1002/ajpa.21000

Bayle P, Braga J, Mazurier A, Macchiarelli R. 2009a. Dental developmental pattern of the Neanderthal child from Roc de Marsal: A high-resolution 3D analysis. Journal of Human Evolution [Internet] 56:66-75. Available from:

http://www.sciencedirect.com/science/article/B6WJS-4TVFYTX-

2/2/e4728d7332772d0ae5000d452a75d1e1

Bayle P, Macchiarelli R, Trinkaus E, Duarte C, Mazurier A, Zilhão J. 2010. Dental maturational sequence and dental tissue proportions in the early Upper Paleolithic child from Abrigo do Lagar Velho, Portugal. Proceedings of the National Academy of Sciences [Internet] 107:1338-1342. Available from: http://www.pnas.org/content/early/2009/12/22/0914202107.abstract

Bermúdez de Castro JM. 1989. Third molar agenesis in human prehistoric populations of the Canary Islands. American Journal of Physical Anthropology 79:207-215.

Bermúdez de Castro JM, Martínez I, Gracia-Téllez A, Martinón-Torres M, Arsuaga JL. 2021. The Sima de los Huesos Middle Pleistocene hominin site (Burgos, Spain). Estimation of the number of individuals. The Anatomical Record [Internet] In press. Available from: https://anatomypubs.onlinelibrary.wiley.com/doi/abs/10.1002/ar.24551 
Bermúdez de Castro JM, Martinón-Torres M, Prado L, Gómez-Robles A, Rosell J, López-Polín L, Arsuaga JL, Carbonell E. 2010. New immature hominin fossil from European Lower Pleistocene shows the earliest evidence of a modern human dental development pattern. Proceedings of the National Academy of Sciences of the United States of America 107:11739-11744.

Bermúdez de Castro JM, Rosas A. 2001. Pattern of dental development in Hominid XVIII from the Middle Pleistocene Atapuerca-Sima de los Huesos site (Spain). American Journal of Physical Anthropology 114:325-330.

Bermúdez de Castro JM, Rosas A, Carbonell E, Nicolás ME, Rodríguez J, Arsuaga JL. 1999. A modern human pattern of dental development in Lower Pleistocene hominids from Atapuerca-TD6 (Spain). Proceedings of the National Academy of Sciences of the United States of America 96:4210-4213.

Bermúdez-de-Castro J-M, Martinón-Torres M, Martín-Francés L, Modesto-Mata M, Martínez-de-Pinillos M, García C, Carbonell E. 2017. Homo antecessor: The state of the art eighteen years later. Quaternary International 433:22-31.

Braga J, Heuze Y. 2007. Quantifying variation in human dental development sequences: An EVO-DEVO perspective. In: Bailey SE, Hublin J-J, editors. Dental Perspectives on Human Evolution. Berlin: Springer-Verlag. p 247-261.

Braga J, Heuze Y, Chabadel O, Sonan NK, Gueramy A. 2005. Non-adult dental age assessment: Correspondence analysis and linear regression versus Bayesian predictions. International Journal of Legal Medicine 119:260-274.

Couvreur TLP, Gort G, Richardson JE, Sosef MSM, Chatrou LW. 2010. Insights into the Influence of Priors in Posterior Mapping of Discrete Morphological Characters: A Case Study in Annonaceae. PLOS ONE 5:e10473.

Crevecoeur I, Bayle P, Rougier H, Maureille B, Higham T, van der Plicht J, De Clerck N, Semal P. 2010. The Spy VI child: A newly discovered Neandertal infant. Journal of Human Evolution 59:641-656.

Daura J, Sanz M, Pike AWG, Subirà ME, Fornós JJ, Fullola JM, Julià R, Zilhão J. 2010. Stratigraphic context and direct dating of the Neandertal mandible from Cova del Gegant (Sitges, Barcelona). Journal of Human Evolution [Internet] 59:109-122. Available from: http://www.sciencedirect.com/science/article/pii/S0047248410000862

Demirjian A. 1996. Dental development, CD-ROM. University of Montreal, Montreal: Silver Platter education.

Demirjian A, Goldstein H, Tanner J. 1973. A new system of dental age assessment. Hum Biol 45:211-27.

Duarte C, Maur'ıcio J, Pettitt PB, Souto P, Trinkaus E, van der Plicht H, Zilhão J. 1999. The early Upper Paleolithic human skeleton from the Abrigo do Lagar Velho (Portugal) and 
modern human emergence in Iberia. PNAS [Internet] 96:7604-7609. Available from: https://www.pnas.org/content/96/13/7604

Duval M, Grün R, Parés JM, Martín-Francés L, Campaña I, Rosell J, Shao Q, Arsuaga JL, Carbonell E, Bermúdez de Castro JM. 2018. The first direct ESR dating of a hominin tooth from Atapuerca Gran Dolina TD-6 (Spain) supports the antiquity of Homo antecessor. Quaternary Geochronology 47:120-137.

Gambier D, Valladas H, Tisn'erat-Laborde N, Arnold M, Bresson F. 2000. Datation de vestiges humains présumés du Paléolithique supérieur par la méthode du Carbone 14 en spectrométrie de masse par accélérateur / Accelerator mass spectrometry radiocarbon dates of human remains from Upper Palaeolithic. Paléo, Revue d'Archéologie Préhistorique [Internet] 12:201-212. Available from: https://www.persee.fr/doc/pal_11453370_2000_num_12_1_1602

García-González R, Carretero JM, Rodríguez L, Gómez-Olivencia A, Arsuaga JL, Castro JMB de, Carbonell E, Martínez I, Lorenzo C. 2009. Étude analytique d'une clavicule complète de subadulte d'Homo antecessor (site de Gran Dolina, Sierra d'Atapuerca, Burgos, Espagne). L'Anthropologie [Internet] 113:222-232. Available from: http://www.sciencedirect.com/science/article/pii/S0003552108001209

Garn SM, Lewis AB, Kerewsky RS. 1963. Third molar agenesis and size reductions of the remaining teeth. Nature 200:488-489.

Guérin G, Discamps E, Lahaye C, Mercier N, Guibert P, Turq A, Dibble HL, McPherron SP, Sandgathe D, Goldberg P, Jain M, Thomsen K, Patou-Mathis M, Castel J-C, Soulier M-C. 2012. Multi-method (TL and OSL), multi-material (quartz and flint) dating of the Mousterian site of Roc de Marsal (Dordogne, France): Correlating Neanderthal occupations with the climatic variability of MIS 5-3. Journal of Archaeological Science [Internet] 39:3071-3084. Available from: http://www.sciencedirect.com/science/article/pii/S030544031200180X

Konigsberg LW, Frankenberg SR. 1992. Estimation of age structure in anthropological demography. American Journal of Physical Anthropology [Internet] 89:235-256. Available from: https://onlinelibrary.wiley.com/doi/abs/10.1002/ajpa.1330890208

Liversidge HM. 2008. Timing of human mandibular third molar formation. Annals of Human Biology 35:294-321.

Liversidge HM, Molleson T. 2004. Variation in crown and root formation and eruption of human deciduous teeth. American journal of physical anthropology 123:172-80.

Macchiarelli R, Bondioli L, Debénath A, Mazurier A, Tournepiche J-F, Birch W, Dean MC. 2006. How Neanderthal molar teeth grew. Nature 444:748-751.

Martín-Francés L, Martinón-Torres M, Pinillos MM de, Bayle P, Fernández-Colón P, GarcíaCampos C, Modesto-Mata M, Carbonell E, Arsuaga JL, Castro JMB de. 2020. Ectopic maxillary third molar in Early Pleistocene Homo antecessor from Atapuerca-Gran Dolina site (Burgos, Spain). American Journal of Physical Anthropology In press. 
Martín-González JA, Mateos A, Goikoetxea I, Leonard WR, Rodríguez J. 2012. Differences between Neandertal and modern human infant and child growth models. Journal of Human Evolution [Internet] 63:140-149. Available from: http://www.sciencedirect.com/science/article/pii/S0047248412000723

Martinón-Torres M, Bermúdez de Castro JM, Gómez-Robles A, Prado-Simón L, Arsuaga JL. 2012. Morphological description and comparison of the dental remains from AtapuercaSima de los Huesos site (Spain). Journal of Human Evolution 62:7-58.

Mincer HH, Harris EF, Berryman HE. 1993. The ABFO study of third molar development and its use as an estimator of chronological age. Journal of Forensic Sciences 38:379-379.

Modesto-Mata M, Dean MC, Lacruz RS, Bromage TG, García-Campos C, Martínez de Pinillos M, Martín-Francés L, Martinón-Torres M, Carbonell E, Arsuaga JL, Bermúdez de Castro JM. 2020. Short and long period growth markers of enamel formation distinguish European Pleistocene hominins. Scientific Reports [Internet] 10:1-12. Available from: https://www.nature.com/articles/s41598-020-61659-y

Moorrees CFA, Fanning EA, Hunt EE. 1963. Age variation of formation stages for ten permanent teeth. Journal of dental research 42:1490-1503.

Moreno D, Falguères C, Pérez-González A, Voinchet P, Ghaleb B, Despriée J, Bahain J-J, Sala R, Carbonell E, Bermúdez de Castro JM, Arsuaga JL. 2015. New radiometric dates on the lowest stratigraphical section (TD1 to TD6) of Gran Dolina site (Atapuerca, Spain). Quaternary Geochronology 30:535-540.

Nanda RS. 1954. Agenesis of the third molar in man. American Journal of Orthodontics and Dentofacial Orthopedics [Internet] 40:698-706. Available from:

https://www.ajodo.org/article/0002-9416(54)90058-5/abstract

Quam R, Sanz M, Daura J, Robson Brown K, Garc'ıa-Gonz'alez R, Rodr'ıguez L, Dawson H, Rodr'ıguez RF, G'omez S, Villaescusa L, Rubio 'Angel, Yagüe A, Ortega Mart'inez MC, Fullola JM, Zilhão J, Arsuaga JL. 2015. The Neandertals of northeastern Iberia: New remains from the Cova del Gegant (Sitges, Barcelona). Journal of Human Evolution [Internet] 81:13-28. Available from: http://www.sciencedirect.com/science/article/pii/S0047248415000214

Raff RA. 1996. The Shape of Life. 1st ed. Chicago: The University of Chicago Press.

Rosas A, Ríos L, Estalrrich A, Liversidge H, García-Tabernero A, Huguet R, Cardoso H, Bastir M, Lalueza-Fox C, Rasilla M de la, Dean C. 2017. The growth pattern of Neandertals, reconstructed from a juvenile skeleton from El Sidrón (Spain). Science 357:1282-1287.

Šešelj M. 2013. Relationship between dental development and skeletal growth in modern humans and its implications for interpreting ontogeny in fossil hominins. American Journal of Physical Anthropology 150:38-47.

Shapira Y, Finkelstein T, Shpack N, Lai YH, Kuftinec MM, Vardimon A. 2011. Mandibular second molar impaction. Part I: Genetic traits and characteristics. American Journal of 
Orthodontics and Dentofacial Orthopedics [Internet] 140:32-37. Available from: https://www.sciencedirect.com/science/article/pii/S0889540611003301

Smith BH. 1986. Dental development in Australopithecus and early Homo. Nature 323:327330.

Smith TM, Tafforeau P, Reid DJ, Pouech J, Lazzari V, Zermeno JP, Guatelli-Steinberg D, Olejniczak AJ, Hoffman A, Radovčić J, Makaremi M, Toussaint M, Stringer C, Hublin J-J. 2010. Dental evidence for ontogenetic differences between modern humans and Neanderthals. Proceedings of the National Academy of Sciences of the United States of America 107:20923-20928.

Tompkins R. 1996a. Human population variability in relative dental development. American journal of physical anthropology [Internet] 99:79-102. Available from: https://www.ncbi.nlm.nih.gov/pubmed/8928725

Tompkins R. 1996b. Relative dental development of Upper Pleistocene hominids compared to human population variation. American Journal of Physical Anthropology [Internet] 99:103-118. Available from: http://dx.doi.org/10.1002/(SICI)10968644(199601)99:1<103::AID-AJPA6>3.0.C0;2-1 


\section{Supplementary Materials}

\section{Supplementary Tables}

Supplementary Table 1: Teeth from the two Sima de los Huesos hominins employed in the calculations of the Bayesian probabilities in respect to the DMS variability in modern humans. Hominins: XVIII and XXV. Position (U = upper; $\mathrm{L}=$ lower); side ( $\mathrm{L}=$ left; $\mathrm{R}=$ right $)$.

\begin{tabular}{lllllll} 
Hominin & XVIII & XVIII & XVIII & XVIII & XXV & XXV \\
\hline Position & U & U & L & L & L & L \\
\hline Side & R & L & R & L & R & L \\
\hline I1 & AT- & AT- & AT- & AT- & AT- & AT- \\
& 2395 & 1143 & 2390 & 2195 & 3882 & 3883 \\
\hline I2 & AT- & AT- & AT-957 & AT- & AT- & AT- \\
& 2280 & 1124 & & 2066 & 3827 & 3937 \\
\hline C & AT- & AT- & AT- & AT-410 & AT- & AT- \\
& 2207 & 2151 & 2165 & & 3886 & 3938 \\
\hline P3 & AT- & AT- & AT- & AT- & AT- & AT- \\
& 2399 & 2036 & 2343 & 2767 & 3941 & 3940 \\
\hline P4 & AT- & AT- & AT- & AT-828 & AT- & AT- \\
& 2189 & 2070 & 2386 & & 3942 & 3939 \\
\hline M1 & AT- & AT- & AT-943 & AT-829 & AT- & AT- \\
& 2076 & 2071 & & & 3933 & 3934 \\
\hline M2 & AT- & AT- & AT- & AT-941 & AT- & AT- \\
& 2175 & 2179 & 1752 & & 3889 & 6579 \\
\hline M3 & AT- & AT- & AT- & AT- & AT- & AT- \\
& 2135 & 2150 & 2277 & 2271 & 3943 & 6580 \\
\hline dm2 & AT- & AT- & AT- & AT-947 & AT- & AT- \\
& 2074 & 2073 & 2398 & & 3935 & 3936 \\
\hline
\end{tabular}


Supplementary Table 2: Homo antecessor (TD6.2) teeth employed in the calculations of the Bayesian probabilities in respect to the DMS variability in modern humans. Three hominins from TD6.2 have been analysed: H1, H3 and H11. Position (U = upper; L = lower); side ( $\mathrm{L}=$ left; $\mathrm{R}$ = right)

\begin{tabular}{|c|c|c|c|c|c|c|c|}
\hline Hominin & $\mathrm{H} 1$ & $\mathrm{H} 1$ & $\mathrm{H} 1$ & $\mathrm{H} 1$ & $\mathrm{H} 3$ & $\mathrm{H} 3$ & H11 \\
\hline Position & $\mathrm{U}$ & $\mathrm{U}$ & $\mathrm{L}$ & $\mathrm{L}$ & $\mathrm{U}$ & $\mathrm{U}$ & $\mathrm{L}$ \\
\hline Side & $\mathrm{R}$ & $\mathrm{L}$ & $\mathrm{R}$ & $\mathrm{L}$ & $\mathrm{R}$ & $\mathrm{L}$ & $\mathrm{R}$ \\
\hline I1 & & & & & & & $\begin{array}{l}\text { ATD6- } \\
112 \\
\end{array}$ \\
\hline I2 & & & & ATD6-2 & $\begin{array}{l}\text { ATD6- } \\
69\end{array}$ & & $\begin{array}{l}\text { ATD6- } \\
112\end{array}$ \\
\hline C & & $\begin{array}{l}\text { ATD6- } \\
13\end{array}$ & ATD6-6 & ATD6-1 & $\begin{array}{l}\text { ATD6- } \\
69\end{array}$ & & $\begin{array}{l}\text { ATD6- } \\
112\end{array}$ \\
\hline P3 & ATD6-7 & $\begin{array}{l}\text { ATD6- } \\
13\end{array}$ & ATD6-3 & & $\begin{array}{l}\text { ATD6- } \\
69\end{array}$ & $\begin{array}{l}\text { ATD6- } \\
69 \\
\end{array}$ & $\begin{array}{l}\text { ATD6- } \\
112 \\
\end{array}$ \\
\hline P4 & ATD6-8 & ATD6-9 & ATD6-4 & & $\begin{array}{l}\text { ATD6- } \\
69\end{array}$ & & $\begin{array}{l}\text { ATD6- } \\
112\end{array}$ \\
\hline M1 & $\begin{array}{l}\text { ATD6- } \\
10 \\
\end{array}$ & $\begin{array}{l}\text { ATD6- } \\
11 \\
\end{array}$ & ATD6-5 & & $\begin{array}{l}\text { ATD6- } \\
69 \\
\end{array}$ & $\begin{array}{l}\text { ATD6- } \\
69 \\
\end{array}$ & $\begin{array}{l}\text { ATD6- } \\
112\end{array}$ \\
\hline M2 & $\begin{array}{l}\text { ATD6- } \\
12\end{array}$ & & ATD6-5 & & & $\begin{array}{l}\text { ATD6- } \\
69\end{array}$ & \\
\hline M3 & & & ATD6-5 & & & $\begin{array}{l}\text { ATD6- } \\
69 \\
\end{array}$ & \\
\hline $\mathrm{dm} 1$ & & & & & & & $\begin{array}{l}\text { ATD6- } \\
112 \\
\end{array}$ \\
\hline $\mathrm{dm} 2$ & & & & & & & $\begin{array}{l}\text { ATD6- } \\
112\end{array}$ \\
\hline
\end{tabular}


Supplementary Table 3: Mineralization stages of H. antecessor (TD6.2) and Sima de los Huesos (SH) teeth following stages defined by Moorrees et al. (1963) for permanent dentition.

\begin{tabular}{lllllllllll} 
Site & Specimen & Position & I1 & I2 & C & P3 & P4 & M1 & M2 & M3 \\
\hline TD6.2 & H1 & Lower & - & Ac & Ac & Ac & Ac & Ac & Rc & Cr3/4 \\
\hline TD6.2 & H1 & Upper & - & - & Ac & Ac & - & Ac & Rc & Cr3/4 \\
\hline TD6.2 & H3 & Upper & - & Rc & R3/4 & R1/4 & R1/4 & Ac & R1/4 & Coc \\
\hline TD6.2 & H11 & Lower & Crc & Crc & Cr3/4 & Coc & Cco & Ri & - & - \\
\hline SH & XVIII & Lower & Ac & Ac & Rc & R1/2 & R1/2 & Ac & R1/2 & Crc \\
\hline SH & XVIII & Upper & Ac & Ac & Rc & R1/2 & R1/2 & Ac & R1/2 & Coc \\
\hline SH & XXV & Lower & Ac & Ac & Ac & Rc & R3/4 & Ac & Rc & R1/4 \\
\hline
\end{tabular}




\section{Supplementary Figures}

Supplementary Fig. 1: Buccal view of the lower dentition of the Sima de los Huesos hominin XXV. dm2s are placed above the crown of their respective P4s. From left to right: right M3 to left M3. Scale bar $=1 \mathrm{~cm}$.

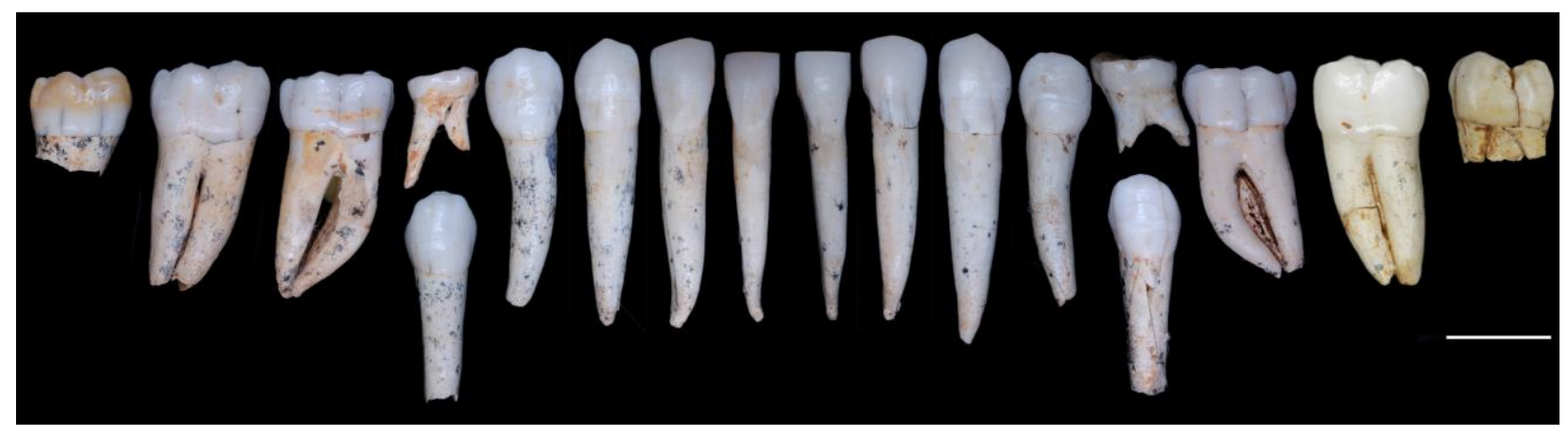

Supplementary Fig. 2: Partially transparent micro-CT images of the buccal view of the preserved teeth of the Gran Dolina H1 specimen. Images not a scale.

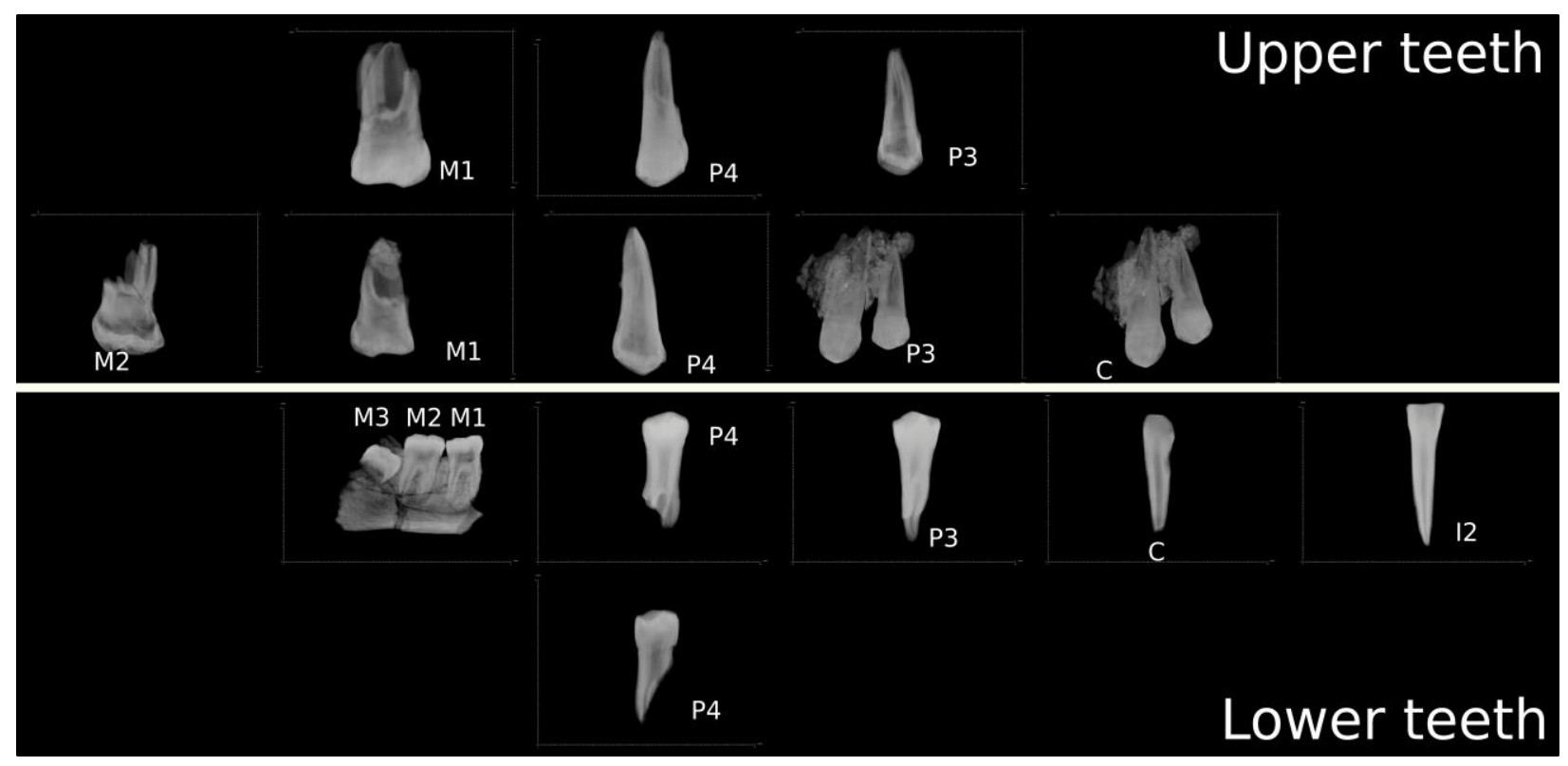


Supplementary Fig. 3: Partially transparent micro-CT images of the buccal view of the preserved teeth of the Gran Dolina H3 specimen. Images not a scale.

\section{Right Maxilla}
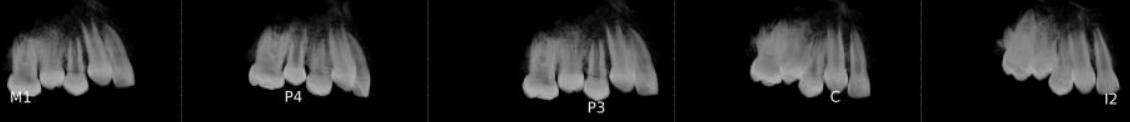

Left Maxilla

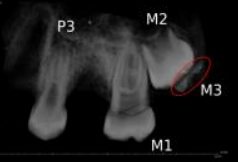

Supplementary Fig. 4: Microcomputerised axial tomographies of the two lower right premolars of the $\boldsymbol{H}$. antecessor hominin 11. (b) buccal; (o) occlusal; (l) lingual; (d) distal. Two scales: $5 \mathrm{~mm}$.

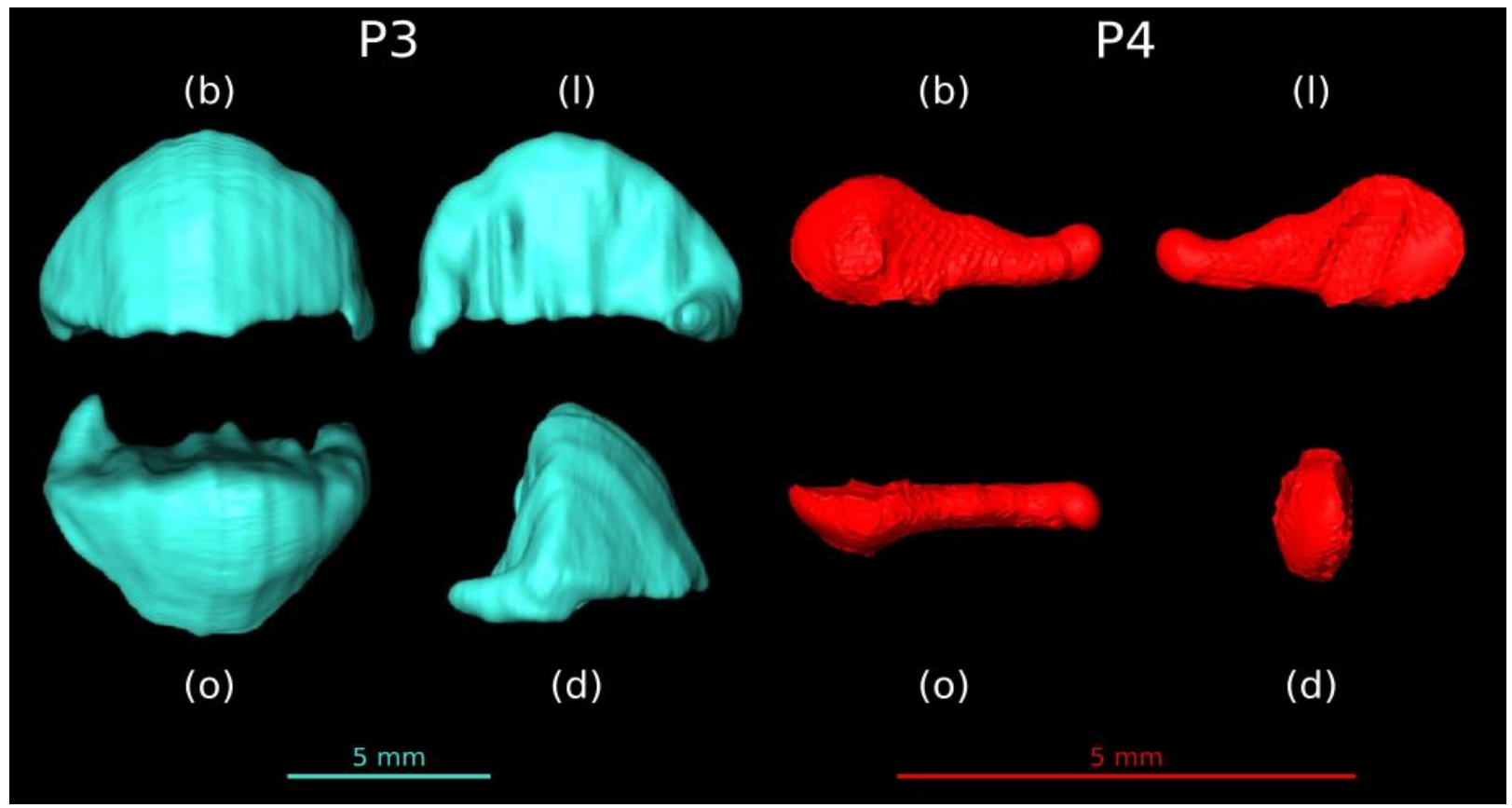

